\title{
ASPECTOS JURfDICOS DO CÓDIGO DE DEONTOLOGIA DA ENFERMAGEM *
}

\author{
Taka Oguisso **
}

OGUISSO, T. Aspectos jurídicos do Código de Deontologia da enfermagem. Rev. Esc. Enf. USP, São Paulo, 13(3):225-232, 1979.

A autora compara as regras do Código de Deontologia do Conselho Federal de Enfermagem e do Código de Etica da Associação Brasileira de Enfermagem com dispositivos equivalentes do Códigos Civil e Penal.

A década de 1970 ficará marcada na História da Enfermagem Brasileira pelo fato de importância fundamental que foi a criação dos Conselhos Federal e Regionais de Enfermagem, consubstanciada na Lei n..$^{\circ} 505$, de 12 de julho de 1973.

Para que esse fate se tornasse na realidade que é, foram necessários vinte e oito anos de trabalho e lutas de um pequeno grupo de enfermeiras da Associação Brasileira de Enfermagem.

Essa realidade está obrigando os enfermeiros a se interessarem pelo estudo da legislação. A importância desse estudo justifica-se pelos seguintes fatores:

1) é por via da legislação que se criam ou se extinguem direitos e deveres;

2) "ninguém se excusa de cumprir a lei, alegando que não a conhece" é o que dispõe o Código Civil Brasileiro, art. $3 .^{\circ}$;

3) esse dispositivo do Código Civil é ratificado pelo Código Penal art. 16, que estabelece: "a ignorância ou a errada compreensão da lei não eximem da pena";

4) o estudo da legislação especifica favorece melhor e maior participação no desenvolvimento da própria profissão.

Segundo Montesquieu, lei é a "relação necessária que deriva da natureza das coisas". Para Comte, são "as relações constantes de sucessão e semelhança entre os fenômenos, em virtude das quais nos é permitido prever certos fenômenos". Cada grupo ou série de fenômenos, constituindo uma ciência, traz consigo suas próprias leis. Estas se dizem, segundo denominação da matéria a que pertencem, leis físicas, leis biológicas, leis sociais, leis econômicas, etc.

No conceito jurídico, originário de lex-legere do latim, lei é a norma ou regra jurídica, escrita e obrigatória, por mais restrito que seja o campo de sua

Trabalho apresentado na I Jornada Regional de Etica da Associação Brasileira de Educaçūo em Enfermagem (ABEE) e da Associação Brasileira de Enfermagem (ABEn) Seção São Paulo.

* Docente Livre de Enfermagem, pela Escola de Enfermagem Ana Néri da Universidade Federal do Rio de Janeiro. Professor Assistente da disciplina História e Legislação da Enfermagem e da Obste. tricla da EEUSP. 
aplicação; emanada de quem - poder ou pessoa investida de autoridade - possa garantir ou assegurar essa obrigatoriedade; com vigência por determinado espaço de tempo numa certa coletividade ou grupo social.

É a lei que institui a ordem jurídica. Jurídico vem de juridicus, direito e dicere, dizer. A qualidade de jurídico exprime o sentido de legítimo, justo, legal, segundo as circunstâncias em que seja aplicado, ao mesmo tempo que revela o ato ou tudo o que se apresenta apoiado na lei ou no direito.

A ordem jurídica instituída pela lei é, portanto, onde se baseia a regulamentação, evolutivamente estabelecida, para manter o equilíbrio entre as relações do homem na sociedade, no tocante a seus direitos e a seus deveres. $\mathrm{Na}$ ordem jurídica está assentado o conjunto de regras obrigatórias, formulado para proteção de todos os interesses e para norma de conduta de todas as ações; e porque ãao estabelecidas pelo próprio homem, impondo-se ao respeito e obrigatoriedade de todos, diferenciam-se das leis naturais.

As leis jurídicas caracterizam-se essencialmente pela sua generalidade ou universalidade e obrigatoriedade.

O caráter e generalidade evidencia-se no princípio de que as leis não se estabelecem ou se prescrevem para cada pessoa, mas sim, para todos em geral. A obrigatoriedade da lei decorre da própria ordem jurídica pré-existente e firma-se na sanção ou coercibilidade imposta para fazer valer a regra que nela se institui. É, assim, por excelência, manifestação de poder. Esse poder originário do próprio grupo social, como um todo, traduz-se, no Estado, pela soberania, ou seja, pelo exercício de um arbítrio, nos limites de um território, e sobre seus habitantes.

A inflexibilidade da lei em relação à sua obrigatoriedade e generalidade é revelada no aforismo dura lex, sed lex, isto é, a lei é dura, mas é lei. Quer isto significar que a lei deve ser obedecida, não importando a regra que venha instituir ou o principio que venha estabelecer.

Semelhante assertiva, entretanto, não significa que qualquer disposição possa ser imposta pela lei. Esta há que obedecer aos princípios da ordem jurídica, sem impor regras ou normas irregulares e absurdas, que fujam aos fundamentos do próprio Direito, firmados em seus preceitos naturais. Portanto, as leis devem sempre visar o bem comum e atender às exigências de bem do próprio homem, com base nas exigências da natureza.

A elaboração formal da lei no Brasil, dentro do regime bicameral, composto de Senado Federal e Câmara dos Deputados, obedece a dispositivo constitucional sobre processo legislativo.

Esse processo, ou ritual, que deve ser seguido na elaboração da lei ou norma jurídica, aplica-se nos casos de emendas à Constituição, leis complementares à Constituição, leis ordinárias, leis delegadas, decretos-leis, decretos legislativos, resoluções e portarias. Entre as leis há uma hierarquia, uma ordem de grandeza condicionando inclusive o espaço de aplicação, a menor ou maior abrangência da generalidade dos cidadãos. Acima de todas, está a lei constitucional, vigente nos limites totais do Estado, para todos os indivíduos, acima de todos os órgãos da soberania e sobre todos os seus titulares. Portanto, pela sistemática jurídica. a 
Constituição é depositária da soberania. Não pode o Congresso Nacional, mediante lei ordinária, contrariar dispositivo constitucional. A revogação de um inciso da Carta Magna deverá seguir o rito complexo da própria elaboração constitucional.

Qualquer lei que se pretenda elaborar, mesmo uma nova Constituição, já encontra em vigor um universo de normas legais; portanto a criação legislativa será sempre um trabalho de complementação, com a finalidade de revigorar a estrutura juridica ,aperfeiçoá-la, suplementá-la, atualizá-la ou conformá-la à evolução social.

\section{A LEI N. ${ }^{\circ} 5.905 / 73$}

Transferidos esses princípios gerais para a legislação especifica da Enfermagem, verifica-se que a Lei n. $5.905 / 73$ constitui uma norma jurídica escrita obrigatória, emanada do Poder competente, vigente por determinado espaço de tempo sobre um grupo social, que é o da enfermagem, nos limites do território que é considerado brasileiro.

Como manifestação legítima de poder do Estado, a Lei n. ${ }^{\circ} 5.905 / 73$ traz em si mesma a sanção, isto é, a força de obrigatoriedade que induz ao cumprimento de seus dispositivods. Em decorrência da promulgação desta Lei, o Ministro de Estado do Trabalho baixou uma Portaria, que também é uma norma jurídica, com força de lei na sua esfera de ação, nomeando os profissionais que comporiam o primeiro Plenário do Conselho Federal de Enfermagem, cuja posse ocorreu no Gabinete do próprio Ministro. Assim, os Membros do Conselho foram investidos de autoridade e competência legal para proceder aos atos administrativos necessários à disciplina e controle do exercício profissional, objetivo principal da entidade.

Um Conselho ou Ordem é um tribunal de ética com função de dizer quais as pessoas que podem exercer a profisão ou ocupação de acordo com a legislação pertinente em vigor; de coibir aqueles que a estiverem exercendo ilegalmente $e$, ainda, de controlar aqueles que a exercem legalmente, para verificar se cumprem com exação suas obrigações, punindo os que se afastam da ética profissional com uma das penas que a Lei faculta.

Embora o País tenha o seu Código Penal, que inclui dispositivos sobre a saúde pública para proteção do cidadão contra profissionais incompetentes, a legislação específica, por ser mais estrita, visa controlar melhor as atribuições de tais profissões ou ocupações, cujo exercício oferece maiores riscos para os consumidores desses serviços.

A legislação de enfermagem não pode, portanto, existir de forma isolada, devendo ser consideradí: no contexto jurídico geral do Pais. Seu propósito fundamental é proteger o bem-estar da sociedade, do indivíduo sadio ou enfermo, estabelecer os requisitos da outorga da licença para o exercício e tomar medidas acauteladoras a fim de que essa licença seja utilzada de forma correta e responsável. Esse aspecto do propósito de qualquer legislação especifica atua, também, como proteção do profissional, reservando a quem está inscrito os direitos e privilégios que a lei estabelecer. 


\section{o Código DE DEONTOLOGIA DE ENFERMAGEM E SEU ASPECTO JURfDICO}

A Lei n..$^{\circ}$ 5.905/73 instituiu a ordem jurídica que representa a expressão da legitimidade, legalidade e justiça, base da regulamentação, evolutivamente estabelecida para manutenção do equilíbrio social nas relações entre os profissionais e ocupacionais da enfermagem e a sociedade, no que tange a seus direitos e deveres.

Pautado nos princípios legais em que foi criado, o Conselho Federal de Enfermagem (COFEN) aprovou o Código de Deontologia de Enfermagem, baixado pela Resolução COFEN n. ${ }^{\circ} 9 / 75$, publicado no Diário Oficial da União (DOU), de 29 de março de 1976. A matéria dessa Resolução constitui "documento balizador da conduta ética do pessoal de enfermagem no exercício de suas atividades". Além desse Código, o COFEN baixou ainda duas outras Resoluções, a de $n .^{\circ} 10 / 75$ e de $n .^{\circ} 10 / 75$, ambas publicadas no DOU, juntamente com o Código de Deontologia de Enfermagem, no dia 29 de março de 1976. A Resolução COFEN n.$^{\circ}$ 10/75 contém o Código de Processo Ético de Enfermagem e a de n. ${ }^{\circ}$ 19/75, o Código de Transgressões e Penalidades.

Obedece, pois, o Código de Deontologia de Enfermagem, assim como os dois outros Códigos que o acompanham, a todos os requisitos legais que os tornam, também, uma regra jurídica formal, obrigatória no espaço de tempo de sua vigência, para toda a coletividade específica por eles abrangida.

O Código de Deontologia de Enfermagem tem por base os postulados da Declaração Universal dos Direitos do Homem, promulgada pela Assembléia Geral das Nações Unidas, em 1948. Estes postulados foram adotados pela Convenção de Genebra da Cruz Vermelha, de 1949, e estão contidos nos Códigos de Ética do Conselho Internacional de Enfermeiras (ICN), do Comitê Internacional Católico de Enfermeiras e Assistentes Médico-Sociais (CICIAMS) e da Associaçāo Brasileira de Enfermagem (ABEn).

A Convenção de Genebra da Cruz Vermelha, de 1949, trata da proteção das pessoas civis em tempo de guerra, quando enfermeiros poderão ser intermediários entre as forças de ocupação $e$ as pessoas necessitadas de assistência. A proteção prevista na Convenção inclui militares e civis enfermos ou feridos, inválidos, crianças, gestantes e anciãos, além de pessoal civil médico e de enfermagem que assistem a essas pessoas em estabelecimentos públicos, designados para esse fim pelo próprio governo.

A Declaração Universal dos Direitos Humanos, os Códigos de Ética das entidades internacionais de classe e o da Associação Brasileira de Enfermagem traçam os princípios básicos da conduta profissional, o que não só supõe a estrita obediência às leis maiores do País, como também impõe aos profissionais e ocupacionais da enfermagem um tipo de comportamento elevado, baseado na moral cristã.

O Capítulo I do Código de Deontologia de Enfermagem trata das responsabilidades fundamentais do enfermeiro.

O Capítulo II dispõe sobre o exercício profissional e estabelece os deveres e proibições relativas ao enfermeiro. 
Os Capitulos III e IV contém os deveres do enfermeiro com relação à classe e demais membros da equipe de saúde.

Todos os dispositivos legais do Código são aplicados, por extensão, no que coube, ao pessoal das outras categorias compreendidas nos serviços de enfermagem.

Cotejando a matéria substantiva do Código de Deontologia e a legislação ordinária contida na Constituição e nos Códigos Civil e Penal vigentes no Brasil, verifica-se que em todos são encontradas normas de conduta disciplinadoras.

Assim, a Carta Magna, art. 153, assegura, aos brasileiros e aos estrangeiros residentes no País, a inviolabilidade dos direitos concernentes à vida ,liberdade, segurança e propriedade, dispondo que "é livre o exercício de qualquer trabalho, ofício ou profissão, observadas as condições de capacidade que a lei estabelece".

Essas condições de capacidade são estabelecidas pelas leis específicas, que é o caso da legislação do COFEN com suas Resoluções.

0 Código Civil Brasileiro, art. 3. , dispõe que "ninguém se escusa de cumprir a lei, alegando que não a conhece".

A responsabilidade civil em casos de ofensa à vida ou à saúde ainda não está tão desenvolvida como nos Estados Unidos ou Canadá, por exemplo, mas o Código Civil (art. 154) prevê indenização ou satisfação do dano causado por médicos, cirurgiōes, farmacêuticos, parteiras e dentistas, sempre que, da imprudência, negligência ou impericia em atos profissionais, resultar morte, inabilitação de servir ou ferimento.

A peculiaridade das atribuições do pessoal de saúde que lida com vidas humanas obriga a que sua atuação se coadune com os preceitos do Código Penal, que estabelece os limites de licitude, além dos quais o ato passa a ser punivel.

Constitui princípio básico do Direito Penal a anterioridade da lei. Esse princípio está consagrado no Código Penal, cujo artigo 1 Ja dispõe que "não há crime sem lei anterior que o defina. Não há pena sem prévia cominação legal"; mas, adverte no art. 16 que "a ignorância ou a errada compreensão da lei não eximem de penas".

Algumas disposições do Código Penal têm vinculação mais direta entre a norma penal e o exercicio da enfermagem.

0 art. 15 desse diploma legal diz que o crime é culposo "quando o agente deu causa ao resultado por imprudência, negligência ou imperícia".

Culpa, no sentido jurídico, é a voluntária omissão de diligência em calcular as conseqüências possíveis e previsíveis do próprio fato. São modalidades de culpa: negligência, imprudência e imperícia.

Negligência é expressão ampla que significa inação, inércia e passividade. Negligente é quando a pessoa, podendo e devendo agir de determinado modo, por indolência ou preguiça mental não age ou se comporta de modo diverso.

Imprudência tem forma ativa. Trata-se de um agir sem a cautela necessária. Consiste em atuar com precipitação, insensatez ou inconsideração, sem atentar para 
a lição dos fatos ordinários nem atender às circunstâncias especiais do caso, etc. RICCIO diz que na negligência não se usam os poderes de atividade e na imprudência faltam os poderes inibitórios.

Imperícia supõe arte ou profissão. Consiste na incapacidade, na falta de conhecimento ou habilitação para o exercício de determinado mister. Pode provir da falta de prática ou da ausência de conhecimentos técnicos da profissão, ofício ou arte. Não se confunde imperícia com erro profissional. Imperito é quem não possui cabedal normalmente indispensável ao exercício de uma profissão. Não existindo essa ignorância não há imperícia, mas erro profissional.

Por ser preceito geral, esse art. 15 do Código Penal atinge qualquer indivíduo, independentemente de sua profissão ou ocupação. Abrange, portanto, o pessoal de enfermagem. O Código de Deontologia, contudo, vai, além, ao estabelecer que "a responsabilidade do enfermeiro por falha cometida em seu trabalho não é diminuída pelo fato de ter sido este executado coletivamente ou em equipe". E, ainda, diz o art. 12 que "o enfermeiro protege o cliente contra danos decorrentes de imperícia, negligência, omissão ou imprudência por parte de qualquer membro da equipe de saúde, alertando o profissional faltoso e, em última instândia, recorrendo à chefia imediata, a fim de que sejam tomadas medidas para salvaguardar a segurança e o conforto do cliente".

Os arts. 124 a 127 do Código Penal tratam do abortamento como um dos crimes contra a vida. Todos esses artigos já provocaram grandes movimentos por parte de grupos de médicos e enfermeiras, no sentido de revogar esse dispositivo. O progresso da ciência reduziu os casos de indicação de abortamento terapêutico. $\mathrm{Na}$ verdade há um conflito entre o Código Civil e o Penal, no que se refere à proteção da vida do nascituro. $O$ Código Civil (art. $4 .^{\circ}$ ) garante plenamente os direitos do nascituro, permitindo até nomeação de curador que torne efetiva a defesa desses direitos. O Código Penal autoriza a violação do direito de viver! E a violação é mais aberrante quando não há o "hipotético risco para a vida da mãe" como é o caso da gravidez resultante de estupro. Dentro de uma sistemática jurídica, cabe especificamente à lei penal policiar os atos anti-sociais, isto é, estabelecer as sanções adequadas à repressão dos atos que violam os direitos do cidadão, garantidos por outras leis substantivas. Essa é a sua função, decorrente da própria natureza da lei penal. Não poderia, portanto, o Código Penal assegurar a alguém a faculdade de violar o direito de outrem, garantido pela lei civil. Equivaleria isto a admitir a subversão da ordem jurídica em nome da própria lei.

Pela enfermagem não pode ser esquecido o art. 25 do Código Penal que dispõe: "Quem, de qualquer modo, concorre para o crime, incide nas penas a este cominadas". E o crime da co-autoria, que o Código de Deontologia capitula no art. 24: " $E$ proibido ao enfermeiro ser conivente, ainda que a título de solidariedade, com crime, contravenção penal, ou ato praticado por colega, que infrinja postulado ético profissional".

O médico e o enfermeiro, como membros da equipe de saúde, são como duas paralelas, cada qual mantendo suas atribuições, que são correlatas e complementares. Conservam, porém, sua responsabilidade integral; têm seus deveres específicos, são orientados para o mesmo objetivo. 
Para não incorrer em co-autoria, o enfermeiro deve recusar cooperar numa intervenção ilícita. Esta ação seria justificada pelos dispositivos do Código de Ética da ABEn e pelo de Deontologia do COFEN, que diz expressamente "ser prop bido provocar aborto, ou cooperar em prática destinada a interromper a gestação".

0 art. 129 do Código Penal trata das lesões corporais. Estas compreendem não só a lesão anatômica, física, mas toda perturbação do equilíbrio funcional do organismo, ou seja, da saúde física ou mental. $O$ crime pode ser praticado por omissão ou comissão. Omissão seria o caso, por exemplo, de deixar de alimentar uma pessoa, de zelar pela sua higiene, de impedir a ação de fatores externos, etc. As lesões podem ser: leves (escoriações, hematomas, provocação de náuseas, vômitos, etc.); graves (fraturas, luxações, enfraquecimento, redução ou diminuição de capacidade); gravíssimas e seguidas de morte.

No exercício da enfermagem podem ocorrer essas lesões corporais tais como fraturas, luxações por quedas do leito, maca ou cadeira; queimaduras por bolsa de água quente, bisturi elétrico, hematomas por injeções mal aplicadas; em geral como decorrência de falta de vigilância, supervisão ou treinamento de pessoal.

A omissão de socorro é outro crime capitulado em lei, no art. 135. Esse artigo traz uma norma de solidariedade sob imperativo legal. O Código de Ética da ABEn, art. 9.', assim como o Código de Deontologia do COFEN, art. 9.०, II, dispõe sobre a proibição do enfermeiro abandonar o paciente em meio a tratamento, sem a garantia de continuidade de assistência.

$\mathrm{O}$ art. 154 do Código Penal trata da violação do segredo profissional.

$\mathrm{Na}$ vida em sociedade o indivíduo necessita recorrer freqüentemente a outros buscando seus conselhos, serviços, assistência, etc., ocasião em que pode revelar fatos que não quer desvendados ou expostos ao conhecimento de terceiros. Tutela-se a liberdade individual relacionada à inviolabilidade de segredos.

0 segredo profissional não deve ser revelado, msmo quando o profissional ou ocupacional é chamado a depor; Código Civil, art. 144, dispõe que "ninguém pode ser obrigado a depor de fatos a cujo respeito, por estado ou profissão, deva guardar segredo".

A revelação do segredo profissional constitui crime previsto no Código Penal, que diz ser crime "revelar a alguém, sem justa causa, segredo, de que tem ciência em razão de função, ministério, ofício ou profissão, e cuja revelação possa produzir dano a outrem".

Para configurar o crime, deve haver nexo causal entre o exercício da atividade e o conhecimento do fato. A lei não se importa com os meios pelos quais se revela o segredo. Não há necessidade da intenção de prejudicar. São irrelevantes os fins e os motivos, a não ser a justa causa ou estado de necessidade, como por exemplo, o caso de moléstia de notificação compulsória.

0 Código de Ética da ABEn, art. 8..$^{\circ}$ e o de Deontologia do COFEN, art. 8. II, dispõem expressamente sobre a matéria, constituindo-os como um dos sagrados deveres do pessoal de enfermagem.

O Código Penal (art. 299) dispõe sobre falsidade ideológica nos seguintes termos: "Omitir, em documento público ou particular, declaração que deve ou 
devia constar, ou nele inserir ou fazer inserir declaração falsa ou diversa da que devia ser escrita, com o fim de prejudicar direito, criar obrigação ou alterar a verdade sobre fato juridicamente relevante: pena reclusão, de um a cinco anos...".

A falsidade ideológica ou intelectual refere-se a documento cuja materialidade é perfeita, mas cujo conteúdo substancial é falso, inverídico. Na enfermagem ocorre nas anotações incorretas, incompletas, falseadas em prontuário, dos fatos relacionados com o cliente ou paciente; portanto, o agente pode cometer esse crime, quer omitindo declaração que devia fazer, quer inserindo ou fazendo inserir declaração falsa ou diversa da que devia ser escrita.

A Lei $n .^{\circ} 2.604 / 55$, regulamentada pelo Decreto $n .^{\circ} 50.387 / 61$, que regula o exercício profissional de enfermagem, ainda em vigor, capitula no art. 14: "São deveres do pessoal de enfermagem: manter perfeita anotação nas papeletas clínicas de tudo quando se relacionar com o doente e com a enfermagem".

\section{CONCLUSÕES}

Este estudo, ainda que incompleto, demonstra ser essencial que os enfermeiros se familiarizem com a legislação profissional específica e com todas as suas implicações.

O propósito da legislação de enfermagem é, principalmente, a proteção do público e a do enfermeiro e de sua equipe.

0 enfermeiro, como profissional legalmente habilitado, deve preparar-se para assumir responsabilidade compativel com seu nível de formação universitária, se quiser ser valorizado e reconhecido em seus direitos; mesmo porque os conhecimentos científicos hoje são de domínio público e a sociedade moderna está cada vez mais conscientizada de seus direitos.

Finalmente, é preciso repetir que a qualidade do preparo determina a qualidade dos serviços de enfermagem. A competência profissional pode ser afetada ou diminuída no decorrer do tempo e pela aparição de novos conhecimentos e técnicas. Somente a educação continuada através de cursos, congressos, seminários, jornadas ou encontros para enfermeiros e demais categorias de enfermagem manterá atualizados os conhecimentos e elevado o nivel de competência.

OGUISSO, T. Legal aspects of the Code of Deontology for nursing personnel. Rev. Esc. Enf. USP, São Paulo, 13(3):225-232, 1979.

The author compares the rules contained in the Code of Deontology, of the Nursing Federal Council, and in the Code of Ethics, of the Brazilian Nurses Association, with the equivalent precepts of the Civil Code and Penal Code of Brazil.

\section{BIBLIOGRAFIA}

1. BRASIL. Ministério do Trabalho Conselho Federal de Enfermagem. Enfermagem, criação e instalação de sua autarquia profissional: relatórlo da gestão 1975-1976. Braślia, s.d.

2. GUIMARAES FILHO, A. Base de cooperaçäo entre médico e enfermeira. In: CONGRESSO EUCARISTICO NACIONAL, 7.०, Curitiba, maio 1960. Curitiba, ABEn, s.d. p. 47-54.

3. NORONHA, E. M. Direito penal. Såo Paulo, Saraiva, 1968 . v. 1.

4. PFIRTER, A. Los convenios de Ginebra del i2 de agosto de 1949: dísposiciones relativas a las enfermeras. In: CONSEJO INTERNACIONAL DE ENFERMERAS. Informe del seminário internacional sobre legislación de entermeria. Basel, Karger, 1972. p 33-42.

5. Silva, O. J. de P. e Vocabulário Jurídico. São Paulo, Forense, 1973, 4 v. 